\title{
Advanced SOGI-FLL Scheme Based on Fuzzy Logic for Single-Phase Grid-Connected Converters
}

\author{
Jin-Sang Park ${ }^{*}$, Thanh Hai Nguyen ${ }^{* *}$, and Dong-Choon Lee ${ }^{\dagger}$ \\ *PLASPO Inc., Ilsan, Korea \\ ${ }^{* * *}$ Department of Electrical Engineering, Yeungnam University, Gyeongsan, Korea
}

\begin{abstract}
This paper proposes a frequency-locked loop (FLL) scheme for a single-phase grid-connected converter. A second-order generalized integrator (SOGI) based on fuzzy logic (FL) is applied to this converter to achieve precise phase angle detection. The use of this method enables the compensation of the nonlinear characteristic of the frequency error, which is defined in the SOGI scheme as the variation of the central frequency through the self-tuning gain. With the proposed scheme, the performance of the SOGI-FLL is further improved at the grid disturbances, which results in the stable operation of the grid converter under grid voltage sags or frequency variation. The PSIM simulation and experimental results are shown to verify the effectiveness of the proposed method.
\end{abstract}

Key words: Current control, Frequency-locked loop, Fuzzy logic, Second-order generalized integrator SOGI), Single-phase converter

\section{INTRODUCTION}

An important control issue in grid-connected power converters is to synchronize the phase angle of the controller with the grid voltage [1], [2]. A phase-locked loop (PLL) system is often used to detect the phase angle of the alternating current (AC) grid voltage in the power quality field, such as the reactive power compensator, uninterruptable power supply and active power filters. In a three-phase system, a quadrature signal generator (QSG) is easily obtained using Park's transformation. However, this transformation is difficult to apply directly to a single-phase system [3]-[5].

A common application of the single-phase grid converter is illustrated in Fig. 1. To estimate the frequency or the phase angle of the single-phase system, several methods have been proposed in the literatures [6], [7]. A method using a recursive discrete Fourier transform (DFT), in which the adaptive band-pass filter is applied to extract the $\mathrm{n}^{\text {th }}$-order harmonic components in a time domain, was proposed in [6], [7]. However, errors in the amplitude and phase angle exist when the time window of the DFT does not match the

Manuscript received Dec. 2, 2013; accepted Feb. 27, 2014

Recommended for publication by Associate Editor Kyo-Beum Lee.

${ }^{\dagger}$ Corresponding Author: dclee@yu.ac.kr

Tel: +82-53-810-2582, Fax: +82-53-810-4767, Yeungnam University *PLASPO Inc., Korea

** Dept. of Electrical Eng., Yeungnam University, Korea

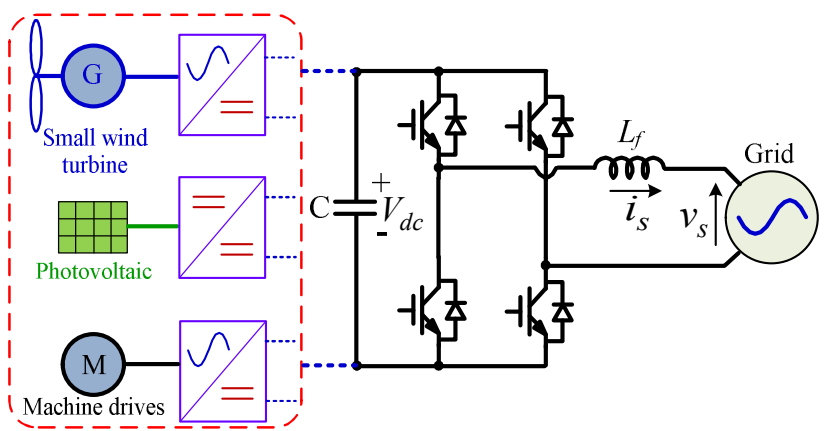

Fig. 1. A typical single-phase grid-connected converter.

fundamental frequency of the input signal. This problem is solved by performing a deadbeat adjustment to the time window or by compensating for the phase error calculated from the DFT [7].

Meanwhile, the PLL of the single-phase system has another category, in which the phase detector (PD) consists of a QSG. Different methods can be used to realize the QSG. A simple scheme is to use the all-pass filter or the second-order low-pass filter to generate the quadrature signal [4], though which the PLL performance deteriorates if the grid voltage contains harmonics. In another method, Hilbert transform has been applied [6], [8], causing the signal to be shifted by 90 degrees while the amplitude remains unchanged. Moreover, several methods employs the inverse Park's transform [9] and a full-order state observer [4], the output performance is of 
which is unsatisfactory when the input voltage is distorted.

Another type of PD, which uses the adaptive filter, was suggested to enhance the performance of the PLL [10]. The adaptive notch filter is based on a least-mean-square (LMS) algorithm with two adaptive weights. The LMS algorithm can be understood as a forward discrete integrator that can be transformed into a second-order adaptive filter. A disadvantage of this method is that a complicated computation, including a trigonometric function is required.

The generalized integrator (GI) has recently been widely used to realize PD without the cosine and sine functions [11], [12]. However, the QSG consisting of the GI is susceptible to parameter variations. That is, if the system frequency is disturbed, a phase detection error occurs.

To overcome these drawbacks, several methods have been suggested [13]-[15]. The most popular scheme is to use the second-order generalized integrator [15]. When the input signal of the SOGI is purely sinusoidal at the constant frequency, the output signal delayed by the phase angle of $90^{\circ}$ is obtained with the same magnitude. However, if the frequency of the input signal is disturbed or distorted, an additional PLL or FLL is required to obtain a correct output signal. Notably, frequency locking is preferred over phase locking for grid synchronizations since system frequency is less variable than the phase angle. In the SOGI-FLL, an integral controller regulates the frequency error to zero. Designing the integral controller is difficult due to a nonlinear characteristic of the frequency error relative to the variation of the central frequency. Therefore, a gain normalization method has been proposed by using small signal analysis [16]-[18], the response of which was slow in case of an abrupt change in input frequency.

This paper is an extended version of the work [19], in which a SOGI-FLL with a self-tuning gain based on the fuzzy logic is proposed for single-phase grid-connected converters. Under grid voltage sag or the frequency variation conditions, the integral gain for the FLL scheme is simultaneously updated by applying the fuzzy logic controller, through which the frequency error and its variation are used as control input variables for the fuzzy logic. The frequency error and variation of the central frequency are then compensated by the adjustable integral gain. With the proposed scheme, the performance of the SOGI-FLL is further improved within the system frequency change. The validity of the proposed method is verified by the simulation and experimental results.

\section{CONVENTIONAL GRID SYNCHRONIZATION Method of Single-PHASE CONVERTER}

\section{A. Basics of the Phase-Locked Loop}

Fig. 2(a) illustrates the basic structure of a PLL system, which consists of three components: PD, loop filter (LF), and voltage control oscillator (VCO). Fig. 2(b) shows the block

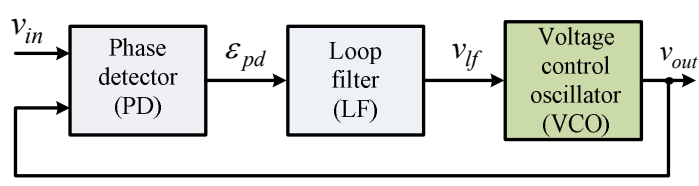

(a)

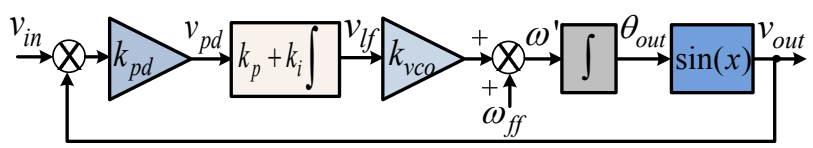

(b)

Fig. 2. Principle of PLL. (a) Basic structure of PLL. (b) Block diagram of the PLL system.

diagram of the PLL system in detail. The PD generates the output signal, which is proportional to the phase difference between the input signal $v_{\text {in }}$ and the output of the VCO block $v_{\text {out }}$. Depending on the type of $\mathrm{PD}$, the high-frequency components or DC signal may appear in the output of the PD. The high-frequency components are eliminated by the LF or proportional integral (PI) controller. The DC component of the $v_{p d}$ causes the frequency of the output signal to coincide with that of the input signal. The VCO block then generates the output signal, the frequency of which is the same as the input frequency [6].

\section{B. Existing SOGI-FLL Method}

A conventional SOGI-FLL scheme based on the adaptive filter has been suggested [17]. In this scheme, an integral gain for the FLL is adjusted by the gain normalization. Fig. 3 shows the block diagram of the SOGI-FLL with a gain normalization, the space-state equations of which are expressed as [16]

$$
\begin{gathered}
\dot{x}=\left[\begin{array}{l}
\dot{x}_{1} \\
\dot{x}_{2}
\end{array}\right]=\left[\begin{array}{cc}
-k \omega^{\prime} & -\omega^{\prime 2} \\
1 & 0
\end{array}\right]\left[\begin{array}{l}
x_{1} \\
x_{2}
\end{array}\right]+\left[\begin{array}{c}
k \omega^{\prime} \\
0
\end{array}\right] v \\
y=\left[\begin{array}{c}
v_{d} \\
v_{q}
\end{array}\right]=\left[\begin{array}{cc}
1 & 0 \\
0 & \omega^{\prime}
\end{array}\right]\left[\begin{array}{l}
x_{1} \\
x_{2}
\end{array}\right] \\
\dot{\omega}^{\prime}=-\gamma x_{2} \omega^{\prime}\left(v-x_{1}\right)
\end{gathered}
$$

where $x=\left[x_{1}, x_{2}\right]^{T}$ and $y=\left[v_{d}, v_{q}\right]^{T}$ are the SOGI-QSG state and output vectors, respectively; $v$ is the input signal; $v_{d}$ and $v_{q}$ are the in-phase and in-quadrature signals of the input, respectively; $\omega^{\prime}$ is the estimated grid frequency; $k$ is the SOGI gain; and $\gamma$ is the integral gain of the FLL.

From Fig. 3, the dynamic of the FLL can be described as

$$
\dot{\omega}^{\prime}=-\gamma \bar{\varepsilon}_{f} .
$$

By considering $\omega^{\prime} \approx \omega,\left(\omega^{\prime 2}-\omega^{2}\right)$ can be approximated as $2\left(\omega^{\prime}-\omega\right) \omega^{\prime}$ for the small signal analysis, (4) can be 


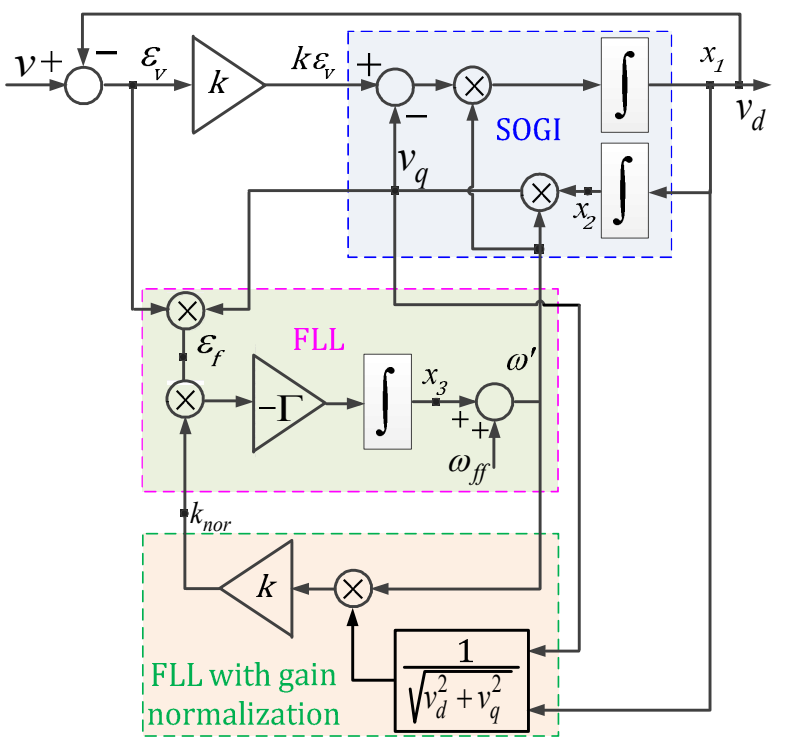

Fig. 3. Block diagram of SOGI-FLL with gain normalization.

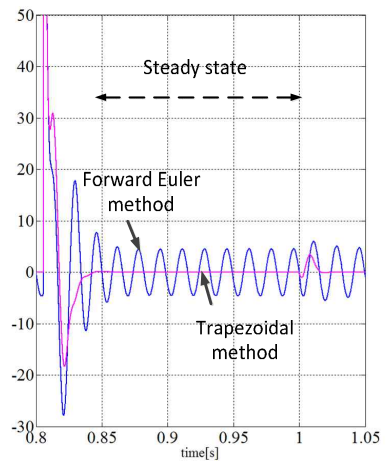

(a)

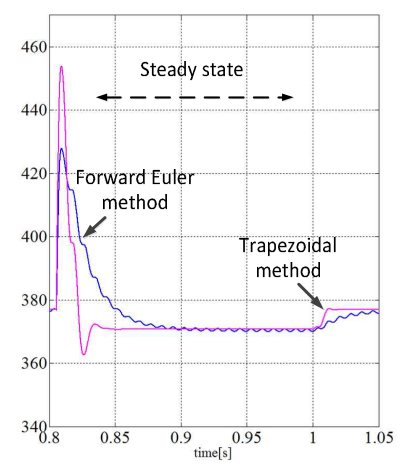

(b)
Fig. 4. Effects of integral operation in a time domain. (a) Frequency error. (b) Estimated central frequency.

rewritten as [16], [17]

$$
\dot{\omega}^{\prime}=-\frac{\gamma V^{2}}{k \omega^{\prime}}\left(\omega^{\prime}-\omega\right)
$$

where $V$ is the magnitude of the input signal.

To achieve the linearized system from the nonlinear dynamics of the FLL, the $\gamma$ should be normalized. The linearized system then becomes independent of the grid voltage and the SOGI gain. In (5), $\gamma$ can be normalized as

$$
\gamma=\frac{k \omega^{\prime}}{V^{2}} \Gamma
$$

where $\Gamma$ represents a new gain, which can adjust the settling time of the frequency estimation loop [17].

From (5) and (6), the transfer function of the frequency estimation loop can be expressed as

$$
\frac{\bar{\omega}^{\prime}}{\omega}=\frac{\Gamma}{s+\Gamma} .
$$

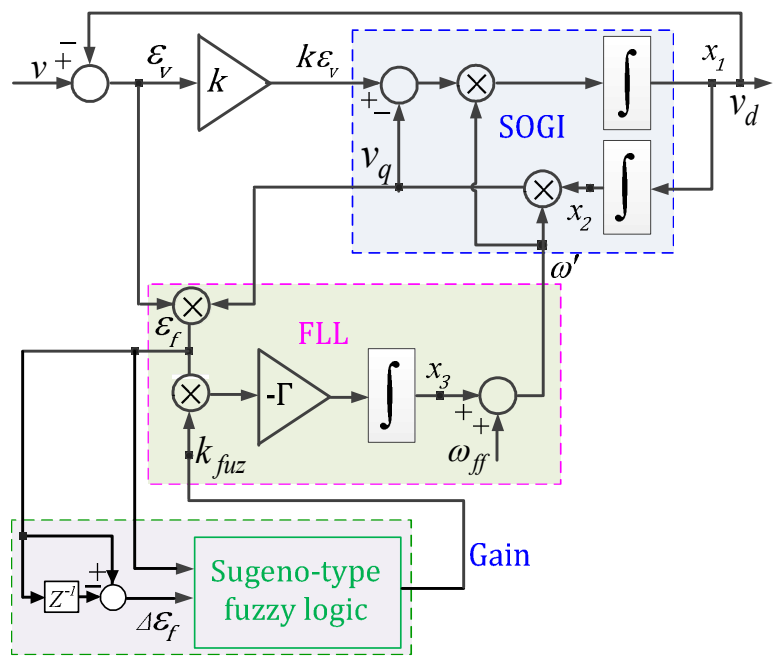

Fig. 5. Block diagram of the proposed SOGI-FLL, based on FL.

In this study, the SOGI parameters are set as $k=1$ and $\Gamma=46$ by using a trial-and-error method.

\section{PRoposed SOGI-FLL BASED ON FuZZY LoGIC CONTROL FOR SINGLE-PHASE CONVERTERS}

The frequency error $\bar{\varepsilon}_{f}$ is a nonlinear function of $\dot{\omega}^{\prime}$ and $\omega$. Accordingly, the linear control technique is unsuitable for use with the SOGI-FLL scheme. When the integrators are implemented in the SOGI scheme in the time domain, the frequency error and the estimated central frequency may have oscillations, depending on the type of digital integrators, the effects of which are shown in Figs. 4(a) and 4(b) [15]. With the forward Euler method, these oscillations are remarkably large, both in the transient and steady states. However, these terms are almost eliminated with the trapezoidal method.

In this research, fuzzy logic is used to determine the value of the FLL gain $\gamma$. Fig. 5 shows the block diagram of the proposed SOGI-FLL method, in which the integral gain, $\gamma$, is adjusted by the fuzzy logic. For this control, the frequency error and its variation are used as control input variables for the fuzzy logic. The fuzzy rules are described as follows: If the frequency error is high [for example, positive-big (PB) or negative-big $(\mathrm{NB})$ ], the fuzzy gain is set to a low value to reduce the integral gain in the FLL. The frequency error is consequently decreased. If the frequency error is low [for example, zero $(Z)]$, the fuzzy gain is set to a high value for rapid estimation. Fig. 6 shows the fuzzification process of the frequency error when the system frequency varies. For instance, we consider that the grid frequency is changed from $60 \mathrm{~Hz}$ to $59 \mathrm{~Hz}$ without any voltage drop. With the inputs of the frequency error and its rate of change, the membership functions are designed to determine the output, which is the gain shown in Fig. 5. 


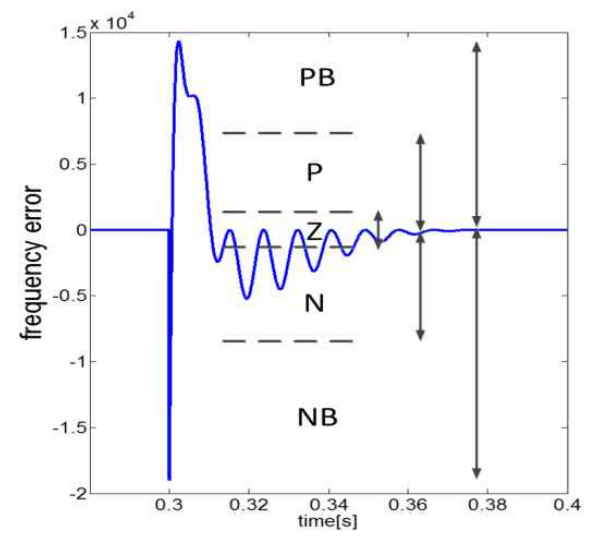

Fig. 6. Fuzzification of the frequency error.
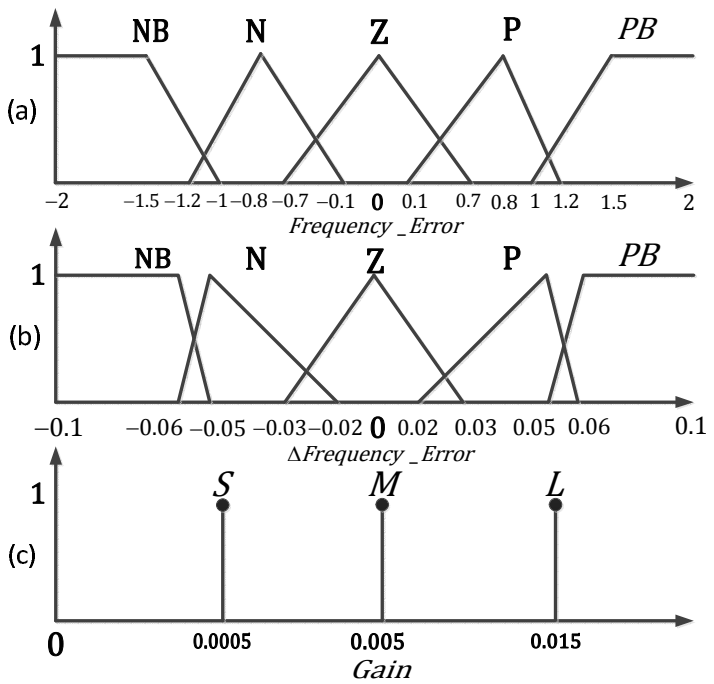

Fig. 7. Membership functions. (a) Frequency error $\left(\varepsilon_{f}\right)$. (b) Variation of frequency error $\left(\Delta \varepsilon_{f}\right)$. (c) Fuzzy output.

TABLE I

RULES OF FUZZY LOGIC CONTROLLER

\begin{tabular}{|c|c|c|c|c|c|c|}
\hline & \multicolumn{7}{|c|}{$\varepsilon_{f}$} \\
\hline \multirow{4}{*}{$\Delta \varepsilon_{f}$} & & $\mathrm{NB}$ & $\mathrm{N}$ & $\mathrm{Z}$ & $\mathrm{P}$ & $\mathrm{PB}$ \\
\cline { 2 - 7 } & $\mathrm{NB}$ & $\mathrm{S}$ & $\mathrm{S}$ & $\mathrm{S}$ & $\mathrm{S}$ & $\mathrm{S}$ \\
\cline { 2 - 7 } & $\mathrm{N}$ & $\mathrm{S}$ & $\mathrm{L}$ & $\mathrm{M}$ & $\mathrm{L}$ & $\mathrm{S}$ \\
\cline { 2 - 7 } & $\mathrm{Z}$ & $\mathrm{S}$ & $\mathrm{M}$ & $\mathrm{L}$ & $\mathrm{M}$ & $\mathrm{S}$ \\
\cline { 2 - 7 } & $\mathrm{P}$ & $\mathrm{S}$ & $\mathrm{L}$ & $\mathrm{M}$ & $\mathrm{L}$ & $\mathrm{S}$ \\
\cline { 2 - 7 } & $\mathrm{PB}$ & $\mathrm{S}$ & $\mathrm{S}$ & $\mathrm{S}$ & $\mathrm{S}$ & $\mathrm{S}$ \\
\hline
\end{tabular}

Fig. 7 shows the membership functions for the fuzzy set of inputs and outputs, in which the linguistic variables are represented by $\mathrm{PB}$, Positive $(\mathrm{P}), \mathrm{Z}$, Negative $(\mathrm{N}), \mathrm{NB}$, Large (L), Medium (M), and Small (S). The grade of the input membership functions is obtained from

$$
\mu(x)=1-\frac{|x-m|}{0.5 w}
$$

where $w$ is the width, $m$ is the coordinate of the point at which the grade of the membership is one, and $x$ is the value of the input variable. In this study, the Sugeno-type fuzzy

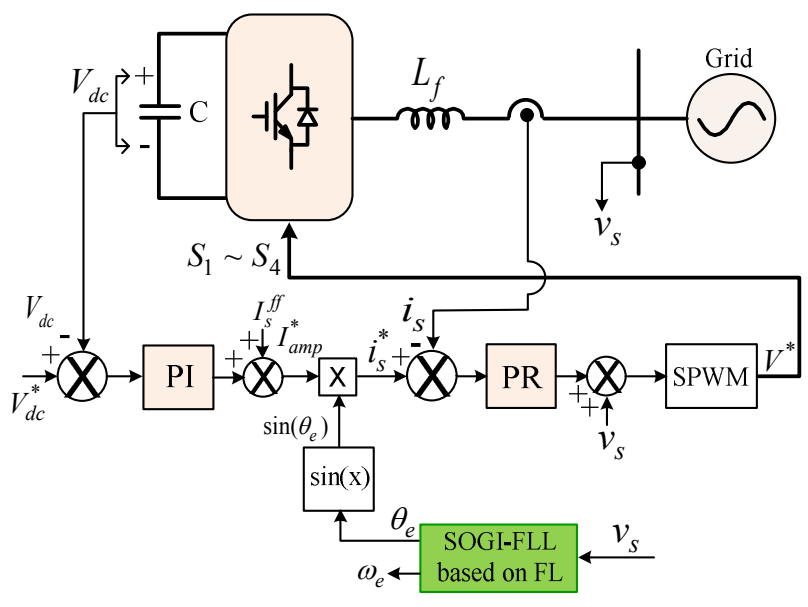

Fig. 8. Control block diagram of the single-phase converter.

interference is applied [20]. Each rule is weighted by the weighting factor, $W_{i}$, which is obtained from the minimum operation as

$$
W_{i}=\min \left\{\mu_{\left.F r_{-} \operatorname{Error}(F), \mu_{F r_{-}} \operatorname{Error}(\Delta F)\right\}} .\right.
$$

The weighted average of all rule outputs that expresses the variation of integral gain, $I_{\text {gain }}$, is calculated as

$$
I_{\text {gain }}=\sum_{i=1}^{N} W_{i} C_{i} / \sum_{i=1}^{N} W_{i}
$$

where $N$ is the total number of rules, and $C_{i}$ is the coordinate corresponding to the respective output or consequent membership function.

Next, a fuzzy rule is expressed as follows:

Rule $_{i}$ : If $\varepsilon_{f}(k)$ is $A_{i}$ and $\Delta \varepsilon_{f}(k)$ is $B_{i}$, then $I_{\text {gain }}$ is $C_{i,}$

where $A_{i}$ and $B_{i}$ comprise the fuzzy subset, and $C_{i}$ is a fuzzy singleton. All fuzzy rules are listed in Table I. For convenience, the inputs of the FL are normalized by the scaling factor of 10,000 depending on the range of the frequency error.

Fig. 8 shows the control block diagram of the singlephase grid-connected converter, to which the proposed SOGIFLL algorithm is applied to detect the phase angle of the grid voltage. The control structure of the converter consists of the DC-link voltage control loop with PI controller and an inner current control loop with a proportional resonant (PR) regulator [21]. The sinusoidal PWM (SPWM) is used to modulate the converter reference voltage.

\section{Simulation RESUlts}

To verify the effectiveness of the proposed method, the PSIM simulation was carried out for the single-phase AC/DC PWM converter. The specifications of the grid converter are listed in Table II. The parameters of the controllers are listed in Table III. The normal grid voltage is at $220 \mathrm{~V}$ and $60 \mathrm{~Hz}$. The DC-link voltage is controlled at $340 \mathrm{~V}$ by the single- 

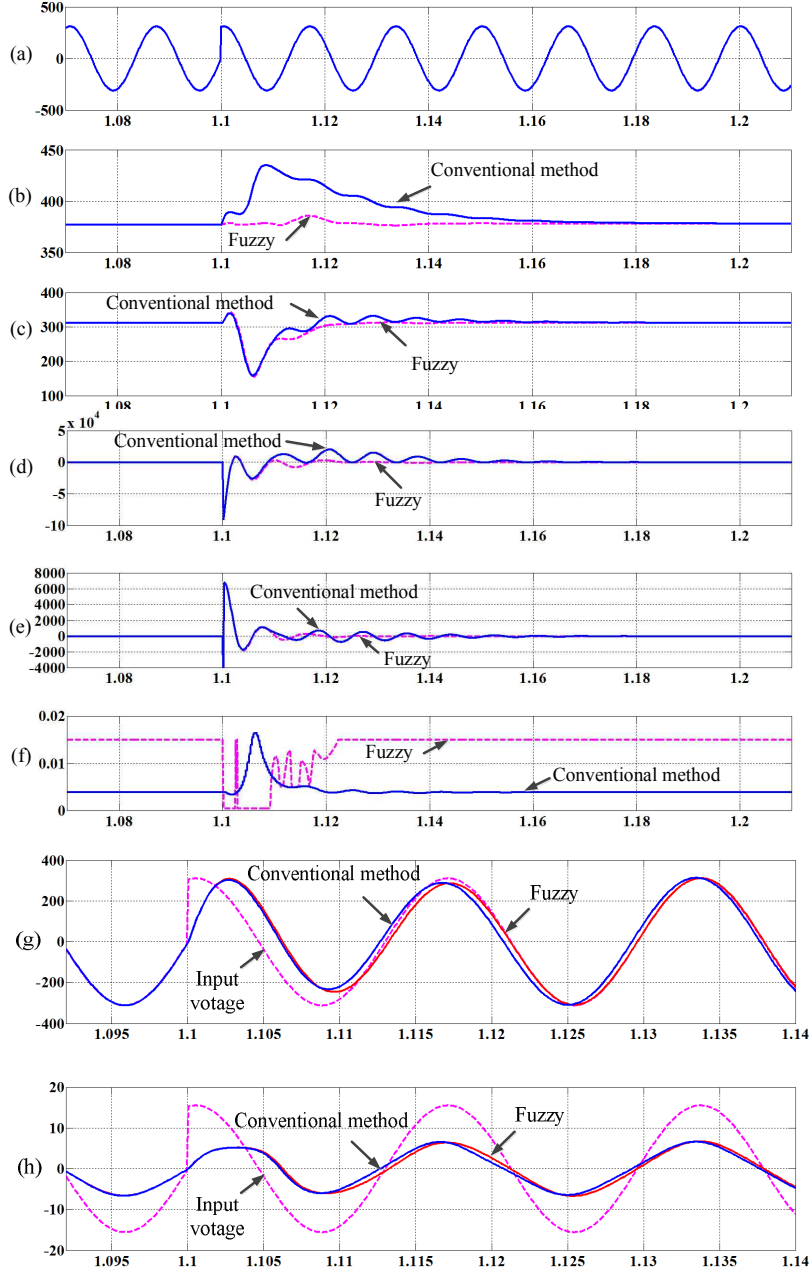

Fig. 9. Performance of conventional and proposed methods. (a) Grid voltage. (b) Estimated angular frequency. (c) Magnitude. (d) Frequency error. (e) Variation of frequency error. (f) Integral gain. (g) SOGI outputs. (h) Grid voltage and current reference.

phase grid converter, the switching frequency of which is 10 $\mathrm{kHz}$.

Fig. 9 shows the performance comparison of the SOGIFLL scheme after applying the conventional SOGI-FLL with gain normalization and the proposed methods based on the fuzzy control when the angular frequency of the grid voltage is changed from $60 \mathrm{~Hz}$ to $60.2 \mathrm{~Hz}$ at $1.1 \mathrm{~s}$. Moreover, at $1.1 \mathrm{~s}$, the phase angle of the grid voltage increases from $0^{\circ}$ to $90^{\circ}$. The grid voltage is shown in Fig. 9(a). The estimated angular frequency, grid voltage magnitude, frequency error, and the variation of the frequency error are illustrated in Figs. 9(b), (c), (d), and (e), respectively. The gain tuning method using fuzzy logic outperforms the conventional approach. As the grid frequency varies, the estimation error of the frequency with the gain normalization method becomes large, which requires a long time to reach the steady state value, as shown in Fig. 9(b). Fig. 9(f) shows the variation of the integral gain for a large frequency error. The value of integral gain with the fuzzy logic is tuned more finely and thus adapted well

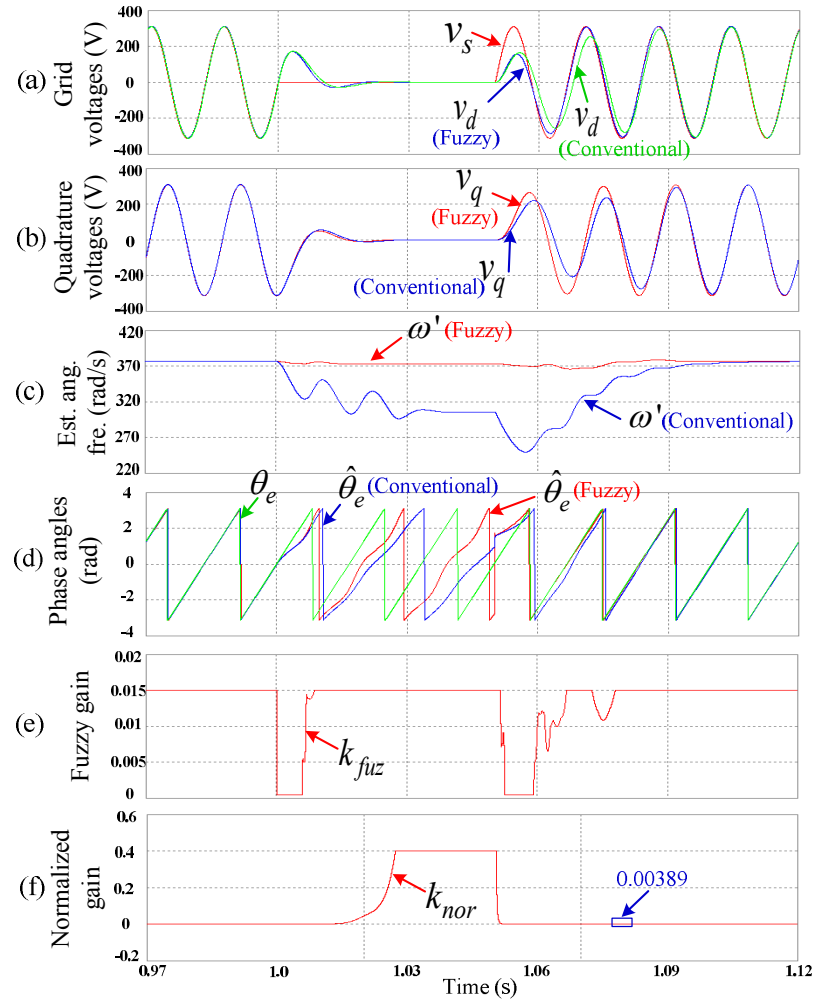

Fig. 10. Performance of the conventional and proposed methods during the grid fault. (a) Grid voltage and estimated in-phase ones. (b) Estimated quadrature voltages. (c) Estimated angular frequencies. (d) Phase angles. (e) Gain in the fuzzy method. (f) Normalized gain.

with the variation of the grid voltage, as is illustrated in Figs. 9(b) to 9 (e). Fig. 9 (g) provides the outputs of the SOGI-FLL, in which the estimated voltage by the conventional method cannot track the grid voltage closely. However, with the proposed method, the estimated voltage rapidly follows the actual current in a cycle. Fig. 9(h) shows the grid voltage and the grid current reference.

Fig. 10 demonstrates the performance of the FLL with the conventional and proposed methods when the grid voltage is fully interrupted from $1.0 \mathrm{~s}$ to $1.05 \mathrm{~s}$, as shown in Fig. 10(a). Figs. 10(a) and 10(b) respectively illustrate the in-phase and quadrature voltage components estimated by the FLL in which the waveforms prove that the use of the proposed method enable the estimation of the grid voltages within a cycle. Meanwhile, the use of the conventional method requires approximately two cycles for the estimated voltage to track the actual current. Fig. 10(c) shows the estimated frequencies. The central frequency is well estimated using the proposed method. However, with the conventional scheme, a large estimation error exists, as shown in Fig. 10(d). The use of the proposed scheme enables the phase angle to be well estimated within a cycle in a manner is faster than that with the conventional scheme. Figs. 10(e) and 10(f) show the integral gain with the proposed and conventional methods, 


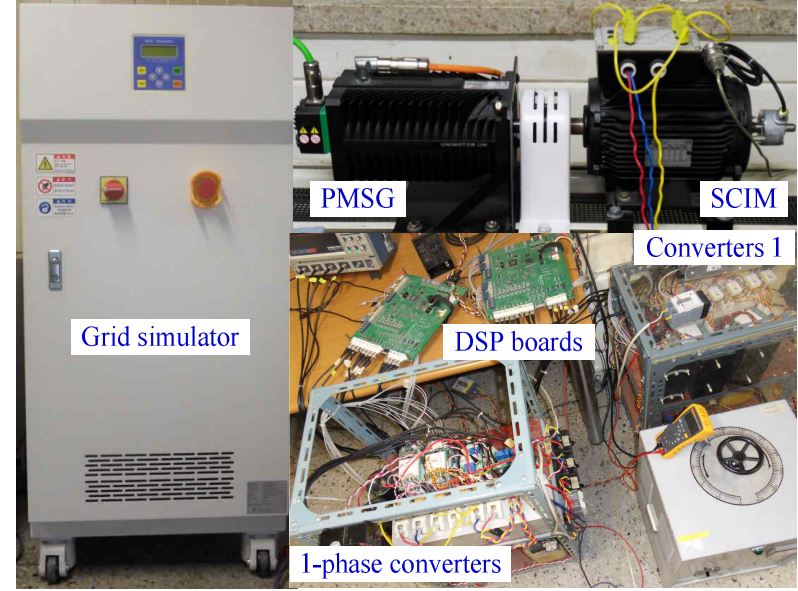

Fig. 11. Experimental setup.

respectively, where the normalized gain, $k_{\text {nor }}$, is increased to its limit, as shown in Fig. 10(f). The limit of the normalized gain is set as 0.4 , which is determined from (6) considering the case of $90 \%$ grid voltage sag.

\section{EXPERIMENTAL RESULTS}

A laboratory prototype of the single-phase grid converter system, which is integrated with a $2.68 \mathrm{~kW}$ PMSG wind turbine, was built for experimental tests to verify the validity of the proposed strategy, as shown in Fig. 11. The parameters of the single-phase converter are the same as those in the simulation, as listed in Table II. For producing the grid voltage disturbances, a grid simulator is used. The normal grid voltage is set as $150 \mathrm{~V}$ and $60 \mathrm{~Hz}$. The DC-link voltage is controlled at $240, \mathrm{~V}$ and the switching frequency of the converter is $10 \mathrm{kHz}$. The sampling time of the current controller and the fuzzy logic controller is at $100 \mu \mathrm{s}$.

The FLL performances by the conventional and proposed methods are shown in Figs. 12 and 13, respectively, under grid interruption of $100 \mathrm{~ms}$, as shown in Figs. 12(a) and 13(a). The in-phase and quadrature voltage components with the proposed method are estimated to be faster than that with the conventional method, particularly after the grid fault clears. Figs. 12(b) and 13(b) show the estimated phase angles. In the conventional FLL, approximately three cycles of tracking time is required after the grid fault clears, whereas only one and a half cycles is required in the proposed method. The central frequency in the conventional method fluctuates significantly, as shown in Fig. 12(c), whereas with the frequency remains close to the actual value of $377 \mathrm{rad} / \mathrm{s}$ in the proposed method, as shown in Fig. 13(c). Fig. 12(d) shows the normalized gain of the conventional method, which reaches the limit. Fig. 13(d) shows the fuzzy gain, which is stable and precisely tuned.

Fig. 14 illustrates the control performance of the grid converter under the voltage sag condition, in which the grid voltage is fully interrupted at $100 \mathrm{~ms}$, as shown in Fig. 13 (a). Fig. 14(b) shows the DC-link voltage, which is still

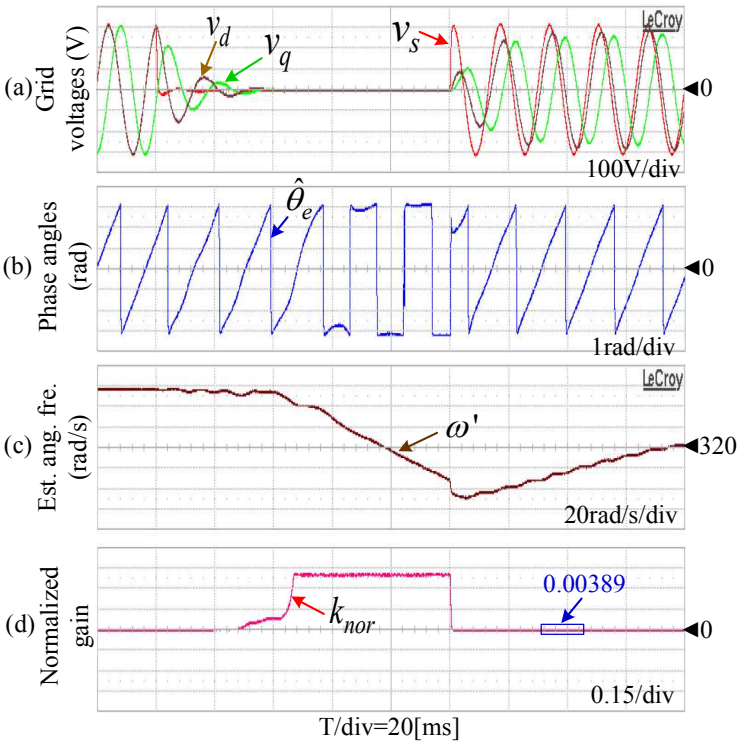

Fig. 12. Performance of the conventional method during the grid fault. (a) Grid voltage and estimated in-phase ones. (b) Phase angle. (c) Estimated angular frequency. (d) Normalized gain.
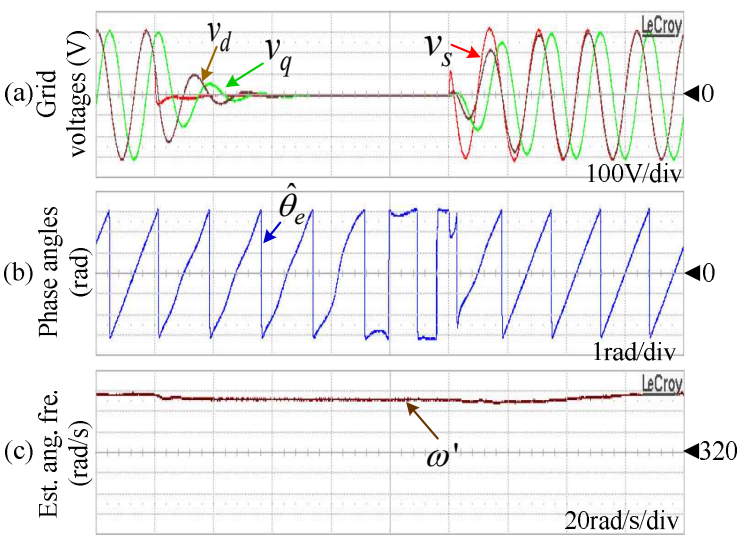

(d)

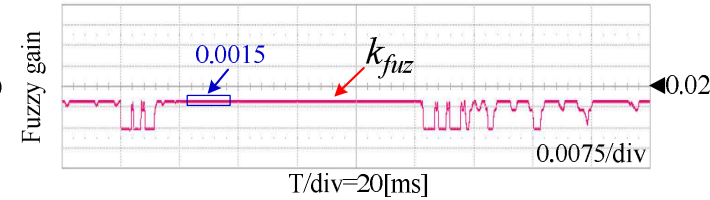

Fig. 13. Performance of the proposed method during the grid fault. (a) Grid voltage and estimated in-phase ones. (b) Phase angle. (c) Estimated angular frequency. (d) Fuzzy gain.

controllable after the grid voltage recovery. Fig. 14(c) provides the grid currents. The grid fault occurrence and recovery, the transient values in the DC-link voltage, and the grid current appear but are within the allowable range. Figs. 14(d) and 14(e) show the precisely estimated frequency and phase angle, respectively. Fig. 14(f) displays the frequency error, which is used for the fuzzy implementation. The fuzzy gain then is updated more precisely during the grid voltage sag, which is shown in Fig. 14(g).

Fig. 15 demonstrates the performance of the SOGI-FLL under the grid frequency variation. Fig. 15(a) shows the grid 


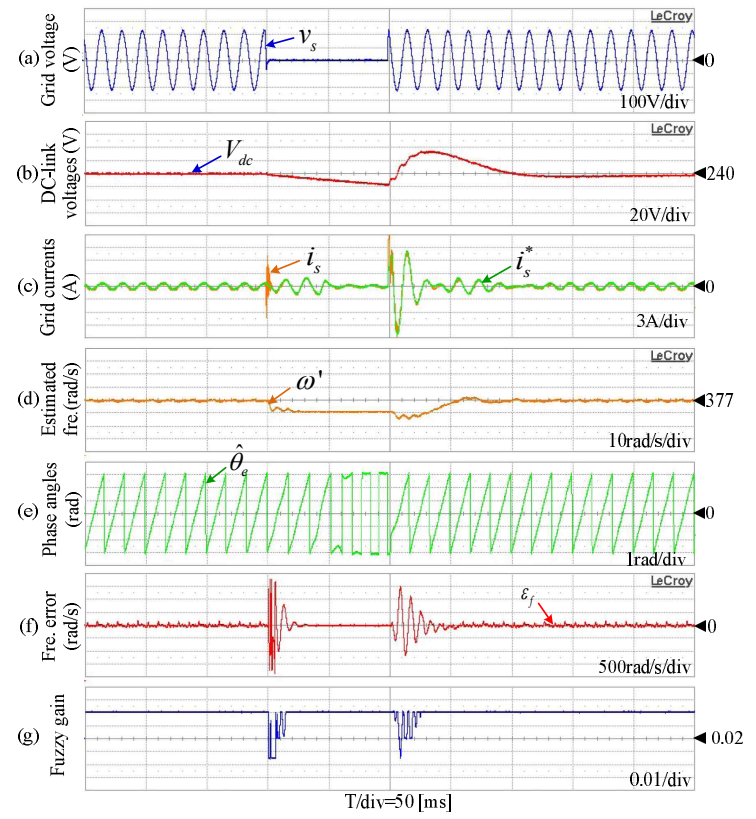

Fig. 14. Performance of the grid converter during the grid fault. (a) Grid voltage. (b) DC-link voltage. (c) Grid currents. (d) Estimated angular frequency. (e) Phase angle. (f) Frequency error. (g) Gain using the fuzzy logic.

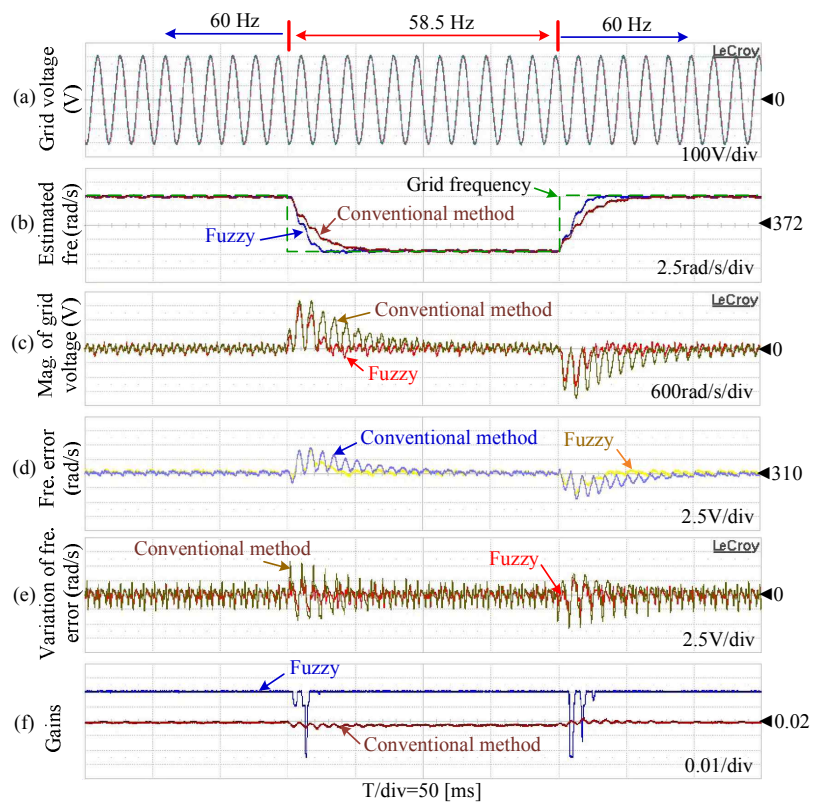

Fig. 15. Performance of the conventional and proposed methods for abrupt changes in the source' frequency. (a) Grid voltage. (b) Estimated frequency. (c) Frequency error. (d) Magnitude of the grid voltage. (e) Variation of frequency error. (f) Integral gain.

voltage, which is adjusted by the grid simulator. The grid frequency is changed from $60 \mathrm{~Hz}$ to $58.5 \mathrm{~Hz}$ without any phase jump. As shown in Fig. 15(b), the estimated angular frequency for the proposed method follows the actual process and provides faster response than that of the conventional approach. Figs. 15(c) and 15(e) indicate the frequency error and its variation for both methods, respectively. With the

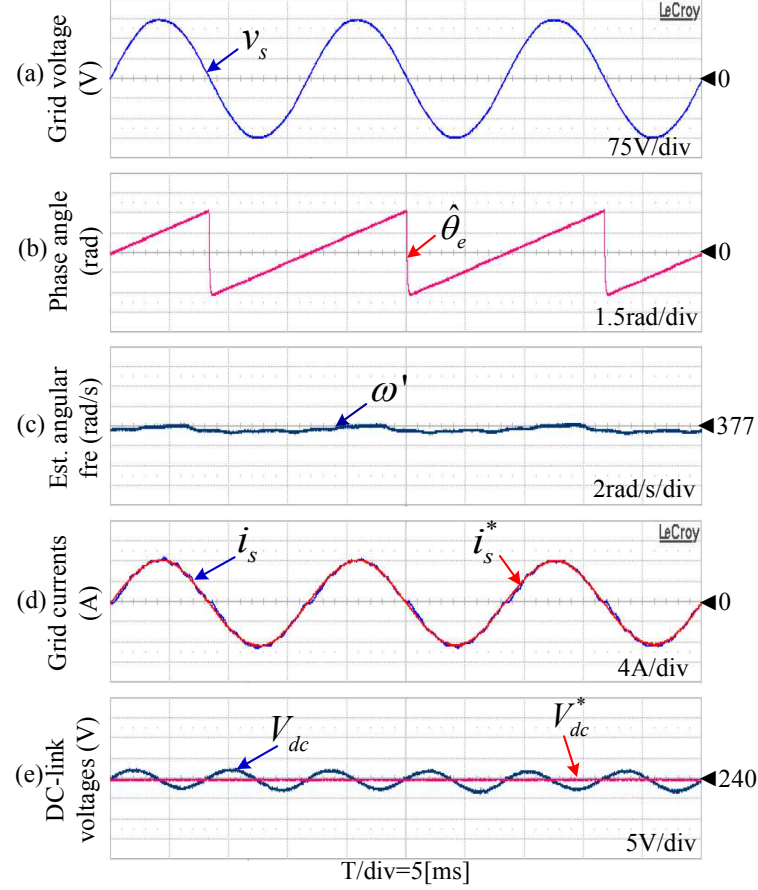

Fig. 16. Control performance of the grid converter. (a) Grid voltage. (b) Phase angles. (c) Estimated angular frequency. (d) Grid currents. (e) DC-link voltages.

proposed method, the frequency error and its variation decay faster. Fig. 15(d) shows the magnitude of the grid voltage. With the proposed method, the grid voltage magnitude reaches the correct value faster. Fig. 15(f) indicates the integral gains, which are tuned more precisely in the fuzzy logic scheme.

Now, we consider the small PMSG wind turbine system of which output is connected to the single-phase grid converter. The control of this small wind system is described in detail in [22]. A cascaded control structure consisting of an outer power control loop and an inner current control loop is applied to the boost converter. As a result, the maximum power point tracking (MPPT) control for the PMSG wind turbine is achieved [22]-[24].

Fig. 16 shows the control performance of the single-phase converter integrated with the small wind turbine. Fig. 16(a) shows the grid voltage, the phase angle and frequency of which are shown in Figs. 15(b) and 15(c), respectively, based on estimation. Fig. 16(d) shows the grid currents, the control performance of which is satisfied. The DC-link voltage is maintained close to the reference value of $240 \mathrm{~V}$, as shown in Fig. 16(e).

Fig. 17 shows the performance of the PMSG wind turbine system. Fig. 17(a) shows the wind speed provided to the turbine blades. Then, with the MPPT control, the generator is mostly proportional to the wind speed, as shown in Fig. 17(b). Fig. 17(c) shows the generator power, which is controlled by the boost converter. Fig. 17(d) shows the boost currents. As shown in Figs. 17(c) and 17(d), the control performances of 


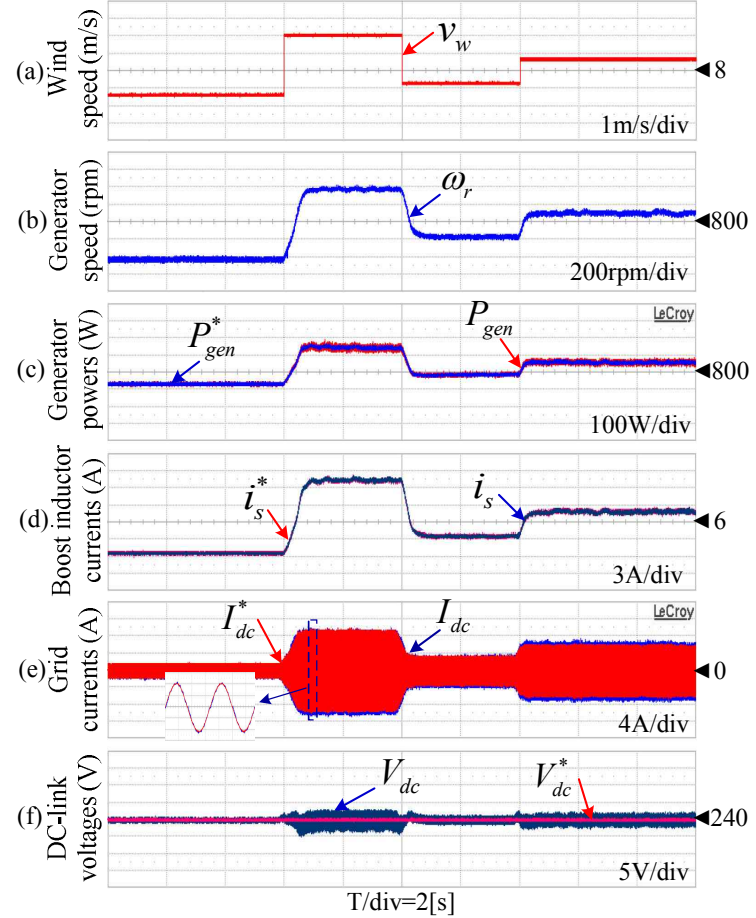

Fig. 17. Control performance of the PMSG wind turbine. (a) Wind speed. (b) Generator speed. (c) Generator powers. (d) Boost inductor currents. (e) Grid currents. (f) DC-link voltages.

the power and current of the boost converter are good. Fig. 17(e) shows the grid currents, the magnitude of which is proportional to the generator power. Fig. 17(f) shows the DClink voltage, which is controlled to be close to its reference. Moreover, the transient value of the DC-link voltage is extremely low under the stepwise change of the wind speed.

Fig. 18 shows the control performance of the PMSG wind turbine system under the grid frequency variation. Figs. 18(a) to $18(\mathrm{c})$ show the grid voltage and its estimated phase angle and frequency, respectively. Fig. 18(c) reveals that the grid frequency changed from $60 \mathrm{~Hz}$ to $58.5 \mathrm{~Hz}$ for $200 \mathrm{~ms}$ and $100 \mathrm{~ms}$, through which the ripple of the estimated frequency during the frequency variation is less than $0.85 \%$. Furthermore, the phase angle is detected accurately. The grid current and DC-link voltage are controlled well, as shown in Figs. 18(d) and 18(e), respectively. Likewise, the DC-link voltage remains unchanged, such that the control of the PMSG was unaffected during the grid frequency change, as confirmed in Figs. 18(f) and 18(g) for the inductor current and generator power, respectively.

\section{CONCLUSIONS}

A novel SOGI-FLL with the self-tuning gain based on the fuzzy logic controller for the single-phase grid-connected converter is proposed in this paper. The SOGI-FLL with conventional gain tuning requires a linearization process of the nonlinear characteristic between the frequency error and

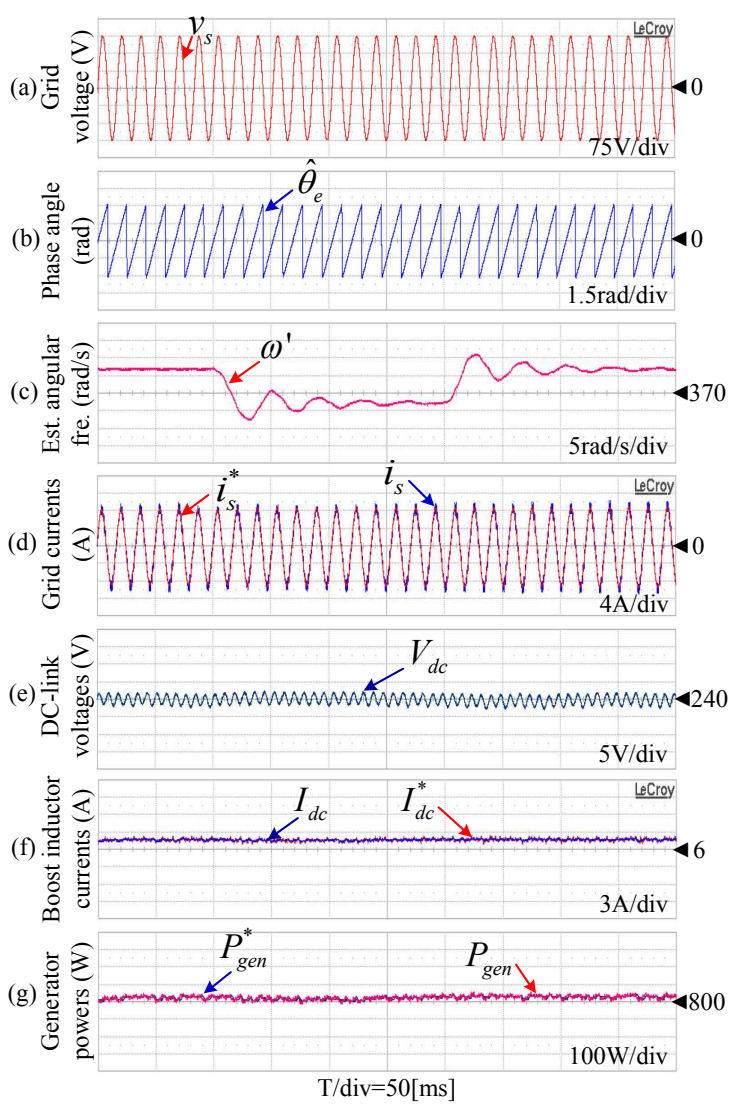

Fig. 18. Control performance of the PMSG wind turbine under grid frequency variation. (a) Grid voltage. (b) Phase angles. (c) Estimated angular frequency. (d) Grid currents. (e) DC-link voltages. (f) Boost inductor currents. (g) Generator powers.

the variation of the central frequency. However, fuzzy logic has solved the nonlinear characteristic for the gain tuning, in which the frequency error and its variations are used as input variables of the FL. With this proposed scheme, the grid converter still functions stably under the grid voltage sag or the grid frequency variation. The validity of the proposed SOGI-FLL method for the single-phase grid converter has been verified by the simulation and experimental results and has thus been applied to a small PMSG wind turbine.

\section{APPENDIX}

The parameters of the grid converter, controller gains, and generator are listed in Tables II and III, respectively.

TABLE II

PARAMETERS OF GRID CONVERTER

\begin{tabular}{|c|c|}
\hline Rated power & $3 \mathrm{~kW}$ \\
\hline Grid voltage/frequency & $220 \mathrm{~V} / 60 \mathrm{~Hz}$ \\
\hline Boost inductance & $3 \mathrm{mH}$ \\
\hline DC-link capacitance & $4,700 \mu \mathrm{F}$ \\
\hline DC-link voltage & $340 \mathrm{~V}$ \\
\hline
\end{tabular}


TABLE III

PI AND PR CONTROLLER GAINS

\begin{tabular}{|c|c|}
\hline $\mathrm{K}_{\mathrm{p}_{\perp}} \mathrm{PI}$ & 1.307 \\
\hline $\mathrm{K}_{\mathrm{i}} \mathrm{PI}$ & 328.72 \\
\hline $\mathrm{K}_{\mathrm{p}_{\_} \mathrm{PR}}$ & 35 \\
\hline $\mathrm{K}_{\mathrm{i} \_} \mathrm{PR}$ & 350 \\
\hline
\end{tabular}

\section{ACKNOWLEDGMENT}

This research was supported by the Yeungnam University Research Grants in 2011.

\section{REFERENCES}

[1] V. M. Moreno, M. Liserre, A. Pigazo, and A. Dell'Aquilla, "A comparative analysis of real-time algorithms for power signal decomposition in multiple synchronous reference frame," IEEE Trans. Power Electron., Vol. 22, No. 4, pp. 1280-1289, Apr. 2007.

[2] F. Blaabjerg, R. Teodorescu, M. Liserre, and A. V. Timbus, "Overview of control and grid synchronization for distributed power generation systems," IEEE Trans. Ind. Electron., Vol. 53, No. 5, pp. 1398-1409, May 2006.

[3] C. H. G. Santos, R. V. Ferreira, S. M. Silva, and B. J. C. Filho, "Fourier-based PLL applied for selective harmonic estimation in electric power systems", Journal of Power Electronics, Vol. 13, No. 5, pp. 884-895, Sep. 2013.

[4] H.-H. Hwang and J.-W. Chio, "Performance improvement of single-phase PLL control using state observer," Trans. of KIPE, Korea, Vol.14, pp. 96-104, Apr. 2009.

[5] M. Monfared, S. Golestan, and J. M. Guerrero, "A new synchronous reference frame-based method for single-phase shunt active power filters", Journal of Power Electronics, Vol. 13, No. 4, pp. 692-700, Jul. 2013.

[6] R. Teodorescue, M. Liserre, and P. Rodriguez, Grid converters for photovoltaic and wind power systems, U.K., WILEY, Ch. 4, 2011.

[7] B. P. McGrath, D. G. Holmes, and J. Galloway, "Improved power converter line synchronization using an adaptive discrete Fourier transform (DFT)," in Proc. IEEE PESC, Vol. 2, pp. 821-826, 2002.

[8] M. Saitou, N. Matsui, and T. Shimizu, "A control strategy of single-phase active filter using a novel d-q transformation," in Proc. IEEE IAS, Vol. 2, pp. 1222-1227, Oct. 2003.

[9] S. M. Silva, B.M. Lopes, B. J. Filho, R. P. Campana, and W. C. Boaventura, "Performance evaluation of PLL algorithms for single-phase grid-connected system," in Proc. IEEE IAS, Vol. 4, pp. 2259-2263, Oct. 2004.

[10] B. Widrow, J. R. Glover Jr, J. M. McCool, J. Kaunitz, C. S. Williams, R. H. Hearn, J. R. Zeidler Jr, E. Dong, and R. C. Goodlin, "Adaptive noise cancelling: Principles and Applications," in Proc. of IEEE, Vol. 63, pp. 1692-1716, Dec. 1975.

[11] X. Yuan, W. Merk, H. Stemmler, and J. Allmeling, "Stationary frame generalized integrators for current control of active power filters with zero steady-state error for current harmonics of concern under unbalanced and distorted operating conditions," IEEE Trans. Ind. Appl., Vol. 38, No. 2, pp. 523-532, Mar./Apr. 2002.
[12] K. de Brabandere, T. Loix, K. Engelen, B. Bolsens, J. V. den Keybus, J. Driesen, and R. Belmans, "Design and operation of a phase-locked loop with Kalman estimatorbased filter for single-phase applications," in Proc. IEEE IECON, pp. 525-530, Nov. 2006.

[13] M. Mojiri and A. R. Bakhshai, "An adaptive notch filter for frequency estimation of a periodic signal," IEEE Trans. Autom. Control, Vol. 49, No. 2, pp. 314-318, Feb. 2004.

[14] M. Mojiri, M. Ksrimi-Ghartemani, and A. Bakhshai, "Time domain signal analysis using adaptive notch filter", IEEE Trans. Signal Process., Vol. 55, No. 1, pp. 85-93, Jan. 2007.

[15] M. Ciobotaru, R. Teodorescu, and F. Blaabjerg, "A new single-phase PLL structure based on second order generalized integrator," in Proc. of IEEE PESC, pp. 1-6, Jun. 2006.

[16] P. Rodriguez, A. Luna, I. Candela, R. Teodorescu, and F. Blaabjerg, "Grid synchronization of power converters using multiple second order generalized integrators," in Proc. of IEEE IECON, pp. 755-760, Nov. 2008.

[17] P. Rodriguez, A. Luna, I. Etxeberria, R. Teodorescu, and F. Blaabjerg, "A stationary reference frame grid synchronization system for three-phase grid-connected power converters under adverse grid conditions," IEEE Trans. Power Electron., Vol. 27, No. 1, pp. 99-112, Jan. 2012.

[18] P. Rodriguez, A. Luna, R. Mujal, R. Teodorescu, and F. Blaabjerg, "Multi-resonant frequency-locked loop for grid synchronization of power converters under distorted grid conditions," IEEE Trans. Ind. Electron, Vol. 58, No. 1, pp. 127-138, Jan. 2011.

[19] J.-S. Park, D.-C. Lee, and T. L. Van, "Advanced singlephase SOGI-FLL using self-tuning gain based on fuzzy logic," in Proc. IEEE ECCE Asia, pp. 1282-1288, May 2013.

[20] B. K. Bose, Modern power electronics and AC drives. Knoxville: Tennessee Univ., Prentice Hall PTR, Ch.11, 2002.

[21] T.-H. Nguyen, D.-C. Lee, and S.-K. Lee, "Sinusoidal current control of single-phase PWM converters under voltage source distortion using composite observer," Trans. of KIPE, Korea, Vol. 16, pp. 466-476, Oct. 2011.

[22] T. H. Nguyen and D.-C. Lee, "A novel current control scheme of grid converters for small PMSG wind turbines under grid voltage distortion," in Proc. IEEE PEMWA, pp. 1-6, Jul. 2012.

[23] Y. Xia, K. H. Ahmed, and B. W. Williams, "A new maximum power point tracking technique for permanent magnet synchronous generator based wind energy conversion system," IEEE Trans. Power Electron., Vol. 26, No. 12, pp. 3609-3620, Dec. 2011.

[24] R. Data and V. T. Ranganathan, "A method of tracking the peak power points for a variable speed wind energy conversion system," IEEE Trans. Energy Convers., Vol. 18, No. 1, pp. 163-168, Mar. 2003.

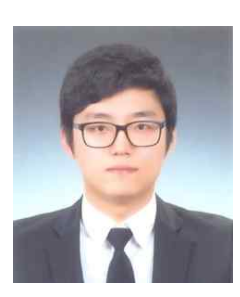

Jin-Sang Park was born in 1985. He received the B.S. and M.S. degrees in Electrical Engineering from Yeungnam University, Gyeongbuk, Korea, in 2011 and 2013, respectively. He is currently with PLASPO Inc., Ilsan, Korea. His research interests include control of power converters, renewable energy systems, and motor drives. 


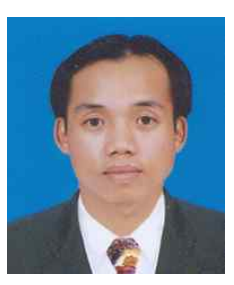

Thanh Hai Nguyen was born in Dong Thap, Vietnam. He received his B.S. degree in Engineering from the Ho Chi Minh City University of Technology, Ho Chi Minh City, Vietnam in 2003, and his M.S. and $\mathrm{Ph} . \mathrm{D}$. in Electrical Engineering from Yeungnam University, Gyeongbuk, Korea in 2010 and 2013, respectively, where he is currently working as a Research Professor. He was an Assistant Lecturer in the College of Technology, Can Tho University, Can Tho, Vietnam from May 2003 to February 2008. His current research interests include power converters, machine drives, HVDC transmission systems, and wind power generation.

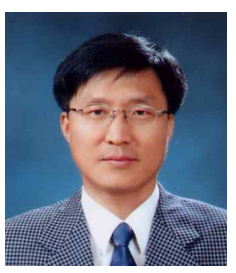

Dong-Choon Lee received his B.S., M.S., and Ph.D. degrees in Electrical Engineering from Seoul National University, Seoul, Korea in 1985, 1987, and 1993, respectively. He was a Research Engineer with Daewoo Heavy Industry, Korea from 1987 to 1988. Since 1994, he has been a faculty member with the Department of Electrical Engineering, Yeungnam University, Gyeongbuk, Korea. As a Visiting Scholar, he joined the Power Quality Laboratory, Texas A\&M University, College Station, TX, USA in 1998; the Electrical Drive Center, University of Nottingham, Nottingham, U.K. in 2001; the Wisconsin Electric Machines \& Power Electronic Consortium, University of Wisconsin, Madison, Wisconsin, USA in 2004; and the FREEDM Systems Center, North Carolina State University, Raleigh, North Carolina, USA from September 2011 to August 2012. His current research interests include ac machine drives, control of power converters, wind power generation, and power quality. Prof. Lee is currently a Publication Editor of the Journal of Power Electronics of the Korean Institute of Power Electronics. 